Bol. Acad. peru. leng. 62. 2017 (253-266)

\title{
Poesía y paisaje en Extravagancias de Marco Antonio Corcuera ${ }^{1}$
}

\author{
Poetry and landscape in Extravagancias \\ (Extravagances) by Marco Antonio Corcuera
}

Francisco TÁvara CóRdova

Instituto de Estudios Vallejianos, filial Lima

\section{Resumen:}

La poesía de Marco Antonio Corcuera (Contumazá, 1917-Trujillo, 2009) se caracteriza por colocar al lector frente a situaciones diversas, entre ellas, escenas donde se presenta una reflexión poética sobre el acto de escribir o componer versos; asimismo, es frecuente encontrar poemas que destacan por la presencia del cromatismo, el mismo que desencadenará una serie de sensaciones en los lectores. Este artículo pretende analizar y explicar cómo se hacen visibles estos detalles reflexivos y cromáticos en el poemario Extravagancias.

\section{Abstract:}

The poetry of Marco Antonio Corcuera (Contumazá, 1917-Trujillo, 2009) is characterized by placing the

\footnotetext{
Este artículo fue presentado como ponencia en el I Congreso Internacional Marco Antonio Corcuera. Homenaje al centenario de su nacimiento, organizado por la Universidad de Piura, la Fundación Marco Antonio Corcuera y la Asociación Educativa y Cultural Ventana Abierta, y realizado en la sede de la Universidad de Piura los días 23 y 24 de noviembre de 2017.
} 
reader to various situations, including scenes with a poetic reflection on the act of writing or composing verses. It is also frequent to find poems that stand out due to the presence of chromaticism, which will trigger a series of sensations in the readers. This article aims to analyze and explain how these thoughtful and chromatic details become visible in his poetry collection Extravaganzas ('Extravagances').

Palabras clave: Marco Antonio Corcuera, poesía, paisaje.

Keywords: Marco Antonio Corcuera, poetry, landscape.

Recibido: 01/11/2017

Aceptado: 26/11/2017

\section{Introducción}

Conocí al Dr. Marco Antonio Corcuera, abogado, poeta y escritor, en la década de los ochenta en la ciudad de Trujillo, capital de la primavera. Nuestra amistad se consolidó cuando participamos como candidatos en una lista de letrados para dirigir los destinos del ilustre Colegio de Abogados de La Libertad, ganamos las elecciones el año 1984 o 1985. Nuestra lista estuvo conformada por los doctores Arnaldo Estrada Cruz (decano), Marco Antonio Corcuera (vicedecano) y yo, Francisco Távara Córdova (director de extensión cultural), a esta directiva también se integró el profesor universitario Dr. Juan Carlos Zavala Sullac. Al poco tiempo de instalarnos en la Junta Directiva, nuestro decano asumió el cargo de prefecto de La Libertad, lo cual significó que el vicedecano, Marco Antonio Corcuera, asumiera 
el decanato del Colegio, y yo el vicedecanato. Entre las actividades institucionales y académicas que realizamos, fuimos a un Congreso Nacional de Abogados que se desarrolló en la ciudad de Arequipa. En una noche de bohemia en la Ciudad Blanca, recuerdo que Marco Antonio Corcuera hizo gala de ser un poeta que improvisaba versos y un gran orador que cautivaba y atrapaba la atención de quienes lo oían.

Marco Antonio Corcuera siempre fue un muy buen amigo no solo en la parte profesional, sino también en sus cualidades y bondades humanas. Nuestras reuniones amicales y profesionales se tornaban también en conversaciones sobre la vida y el proceso de aprendizaje que significa el paso de los años. Cuando me presentó a su digna esposa y algunos de sus hijos, entre ellos, a Marco, abogado y, ahora, notario de la ciudad de Trujillo, incansable conversador y poseedor de un fino humor, supe en ese momento de dónde procedía la fuente de su felicidad y alegría. Y es que Marco Antonio Corcuera no andaba renegando o maldiciendo. Tenía para sus amigos, e incluso para quienes no lo eran, una palabra y un gesto amistoso. Cuando conocí su copiosa y nutrida biblioteca, en la Av. Maniche, pude comprender de dónde provenía el manantial de su sabiduría y la fuente de sus conocimientos.

Poco antes de terminar el año 2001, las responsabilidades y retos profesionales en la Corte Suprema hicieron que me estableciera en Lima. No pudimos seguir frecuentándonos, al enterarme por la prensa y los amigos de su sensible fallecimiento, recordé nuestras experiencias en Trujillo, evoqué su memoria con mucho afecto y respeto. Marco Antonio Corcuera pertenece a 
aquellos seres humanos que, por sus cualidades y calidades, y por su obra, trascienden las fronteras de la efímera existencia.

He visto conveniente contar estos breves pasajes de mi experiencia de conocer a Marco Antonio Corcuera para tributarle también un homenaje a su memoria como amigo, colega y ser humano. A continuación, expondré algunas ideas sobre su poesía.

La poesía de Marco Antonio Corcuera (Contumazá, 1917-Trujillo, 2009) se caracteriza por colocar al lector frente a situaciones diversas, entre estas, escenas donde se presenta una reflexión poética sobre el acto de componer versos; asimismo, sus poemas destacan por presentar verso a verso una amplia gama de elementos paisajísticos tanto como reflexiones poéticas sobre algunas figuras cruciales para la literatura universal, por ejemplo, César Vallejo y Émile Zola. En esta ponencia pretendo analizar y explicar cómo se hacen visibles los detalles reflexivos sobre la poesía, la imagen que se construye del poeta peruano César Vallejo y algunos elementos del paisaje presente en el poemario póstumo Extravagancias (2016). Para ello comentaremos tres poemas que desde su título llaman la atención, se trata de «Yo no sé qué escribir», «Vallejo»y «Cajamarca».

\section{1. «Yo no sé qué es escribir» o la búsqueda de la pala- bra poética precisa}

\section{Yo no sé qué escribir}

Yo no sé qué escribir,

he tomado la pluma inconsciente

para ver si gotean mis ansias, 
y salpican las piras de mi alma.

Pongo un punto y una raya

y se estanca el raudal de las voces,

y está a punto de salir por mi cara.

No sé ni lo que pienso, pero no;

debo decir algo, ¿cómo voy a quedar en silencio,

cómo va a estancarse

la tinta en el pobre tintero

y quedar inactiva e inquieta

mi pluma de acero?

No, me arriesgo ya,

en las alas del hálito vienen

las ideas que quiero grabar.

Al punto y a la raya les agrego

un paréntesis largo que no cerraré,

puntos más puntos, signos más signos,

$\mathrm{y}$ al final un paréntesis inconcluso

que no he terminado de encerrar

a ese tropel de sentimientos

que hacen un nido de mi alma

y convierte a mi alma en un mar.

(Corcuera 2016: 75)

Como se podrá apreciar, el poema escenifica la imposibilidad de escribir. Este hecho frustrante se produce, según sugieren los versos, por la imposibilidad de apresar los sentimientos dentro de los elementos formales que constituyen el poema; es decir, el poeta parece decir con sus versos que resulta infructuoso contener el universo espiritual y la intensidad afectiva dentro de las formas poéticas. Como acabamos de leer, el poema concluye con los versos que informan que el mundo afectivo aún ha quedado sin expresarse completamente. Esta reflexión poética que se propone coincide con una de las ideas que Octavio Paz expuso a mediados del siglo XX en el libro 
El arco y la lira (1956), decía el Premio Nobel de Literatura (1989) que existe una diferencia fundamental entre poema y poesía, pues mientras el primero es una estructura que se puede hallar plasmada en versos y estrofas, la segunda resulta menos perceptible y más espiritual, la poesía es:

conocimiento, salvación, poder, abandono. Operación capaz de cambiar al mundo, la actividad poética es revolucionaria por naturaleza; ejercicio espiritual, es un método de liberación interior. La poesía revela este mundo; crea otro. Pan de los elegidos; alimento maldito. Aisla; une. Invitación al viaje; regreso a la tierra natal. Inspiración, respiración, ejercicio muscular. Plegaria al vacío, diálogo con la ausencia: el tedio, la angustia y la desesperación la alimentan. Oración, letanía, epifanía, presencia (Paz 1956: 13).

El poema «Yo no sé qué escribir» se inserta dentro de la línea reflexiva de Octavio Paz ya que distingue claramente entre la palabra y lo que esta contiene. Los versos sugieren que existe siempre un sentido que la palabra no puede contener. El drama expresivo que el poema nos presenta, en tal sentido, es el de la búsqueda de la palabra precisa que contenga y exprese el mundo interior del poeta, una palabra que logre ser testimonio, experiencia de los sentidos, más que, como se refiere en el poema: «puntos», «rayas», «paréntesis», «puntos más puntos», «signos más signos» que no «terminan de encerrar / a ese tropel de sentimientos» (75). De este modo, "Yo no sé qué escribir» se plantea como una especie de poema que contiene la síntesis de una poética que considera el quehacer del poeta como 
una constante búsqueda de la palabra que exprese con rotundidad la experiencia de los sentidos. Esta idea se define cuando analizamos una de las notas que Marco Antonio Corcuera escribió para el número 47 de los Cuadernos Trimestrales de Poesía (1972), que estuvo dedicado al poeta Wilfredo Torres Ortega. El sintético texto titulado "Qué es la poesía» bien puede servir como resumen de las ideas que aprovecha de otros autores para expresar lo que piensa sobre la poesía; así, suscribe entre comillas que la poesía es una forma de conocimiento, un «testimonio terrible y alegre y triste y esperanzado de nuestra permanencia en el mundo", es el testimonio que oímos tras los versos del poema «Yo no sé qué escribir»y en otros poemas donde el verso se plantea como un testimonio de la experiencia en el mundo.

\section{2. «Vallejo» o el sentido de la vida}

La figura de César Abraham Vallejo Mendoza es otro de los motivos que llama la atención de Corcuera. El poema que le compone es breve, y tiene como título «Vallejo», este va acompañado de una nota al pie que consigna la siguiente información:

Este bello poema es acaso uno de los homenajes más tempranos rendidos a César Vallejo. MAC retoma el símil del cóndor que el propio Vallejo utilizó en 1916 cuando saludó a Víctor Raúl Haya de la Torre con estas palabras: "Yo poeta, brindo mi copa por este pichón de cóndor [...] Yo profeta [...] Anuncio que volará alto, y será grande... grande». Como se sabe, la expresión «pichón de cóndor» la volverá a usar Vallejo en su poema «Huaco», incluido en Los heraldos negros (cursivas en el original). 
La nota es reveladora, pues se trataría de uno de los poemas que Corcuera escribe tempranamente al poeta universal, y donde lo presenta mediante la figura del «cóndor». Este dato adquiere mayor significación cuando lo contrastamos con la información sobre los primeros poemas que se le escriben a Vallejo tras su muerte en 1938, veamos:

En abril de 1958, la revista Cuadernos Trimestrales de Poesía, bajo el título «Es como si contaran mis pisadas», $\mathrm{N}^{\circ} 19$, conmemorando los 20 años de la muerte del vate [César Vallejo], recopila los poemas dedicados a este poeta, en las que se incluyen poemas de: Pablo Neruda (Chile), Carlos Castro Saavedra (Colombia), Xavier Abril (Perú), Alfredo Cardoña Peña (Costa Rica), Gerardo Diego (España), Gustavo Valcárcel (Perú), Leopoldo Panero (España), Felipe Arias Larreta (Perú), Oscar Acosta (Honduras) y Antenor Samaniego (Perú). Todos ellos incluyendo el poema de Felipe Arias Larreta (que se sindica como el primer poeta que le dedica un poema a Vallejo en 1938) hacen alusión al Vallejo fallecido, y a la estela de su partida, mas no al poeta vivo, como sí lo hace MAC incluyendo la figura / metáfora — del cóndor-que el mismo Vallejo usara en su brindis saludando a Haya de la Torre y que probablemente lo supo por el mismo Antenor y otros amigos presentes a los que MAC visitaba desde muy joven ${ }^{2}$.

Según esta información, el poema de Corcuera sería el primero que se le dedica a Vallejo en vida. Leámoslo a continuación:

2 Agradezco a Marco Antonio Corcuera García, hijo del poeta, quien me proporcionó esta valiosa información que permanece aún inédita, con ella se puede realizar el contraste sobre el poema de MAC y el que escribió el estudioso trujillano Felipe Arias Larreta. 


\section{Vallejo}

Es un jirón del Ande pensativo

en el mutismo de la sierra helada.

Es el fulgor de un pensamiento esquivo

que va llevando sutileza y ama.

Es el cantar de un pájaro en el nido y es el atisbo cruel de una amenaza, es la llama de amor y es el quejido, el gran vuelo del cóndor que avanza.

(Corcuera 2016: 127)

Los primeros versos no pretenden destacar ninguna filiación biográfica ni poética, es decir, no se describen situaciones que le tocaron vivir al poeta de Santiago de Chuco, los versos presentan la imagen de un Vallejo como símbolo de la sensibilidad y el pensamiento, por ello, desde las primeras líneas se definen las correspondencias precisas, así, Vallejo es una herida pensativa, una luz, una melodía y una llama de amor. La brevedad del poema puede engañar al lector si es que presupone que su alcance semántico es también escueto. En realidad, el encadenamiento de los versos hace que la imagen de Vallejo resulte multifacética, esto es, Vallejo es muchos. Él significa: una herida, un pensamiento, una actitud; es decir, no solo poesía, no solo imagen artística pura, sino humanidad, sentido, pensamiento, un modo de encarar la historia de la vida; de este modo el poema «Vallejo» estaría proporcionando una de las primeras imágenes sobre el poeta vivo y asociado no solo con la poesía, sino también con la vida y el sentido histórico y humano de la misma. 


\section{3. «Cajamarca», cromatismo, musicalidad y espiritua- lidad}

De los tres poemas que comento, «Cajamarca» es el más extenso y el que podría representar la línea de poemas cuya orientación pone en escena coloridos paisajes. No transcribiré completamente el poema, más bien presentaré algunos de sus versos donde considero que se sintetizan muy bien las características propias del cromatismo paisajista:

\section{Cajamarca}

Cajamarca, la ciudad bella, de mis ensueños y de mi pena, ciudad andina de mis amores $\mathrm{y}$ mis pesares, porque estoy lejos [...]

(Corcuera 2016: 142)

Desde su título, el poema establece una conexión con un escenario geográfico "Cajamarca», ciudad cuya importancia para la historia nacional es fundamental. Pero el poema no incide todavía en esta perspectiva histórica. No quiere ser un poema-crónica desde una mirada ajena al lugar. Los primeros versos lo expresan con claridad. Se trata de la presentación de la ciudad, pero a través de ella, se presenta también la condición migrante del poeta; es decir, aquella bella ciudad es el lugar donde se habitó en algún momento, y que en la condición migrante del poeta solo queda el recurso de la memoria para hacerla presente con toda la carga nostálgica. Esta imagen sobre la telúrica procedencia establece también un juego de tiempo entre el pasado y el presente, 
sobre todo para que el paisaje urbano y la naturaleza no se presenten como escenarios pétreos e inmóviles. Completemos estas ideas con otra imagen, para ello, analicemos los siguientes versos del mismo poema, aunque mejor sería decir, versos sobre la misma ciudad:
Ciudad del Cumbe, mística y bella, do el agua es clara y el aire puro, ciudad del Ande, joya norteña, del Cuzco hermana por su hermosura, joyel purpúreo de ensoñaciones, campo propicio de la alegría, nido do se hallan fulguraciones de la forjada quimera mía.
Fronda de arpegios y dulces trinos, de pampa esbelta, vetusta y quieta, de hermosos lares y de caminos por donde cruza nuestro indio atleta.

(Corcuera 2016: 142)

Se trata de versos que destacan por el cromatismo y la musicalidad, es como si existiese una intencionalidad expresa para producir en el lector una actitud de asombro frente a la belleza colorida y sonora del paisaje. Si bien estas palabras que pintan los escenarios naturales y urbanos pueden hacernos pensar que se trata solo de unos versos que pasan y repasan superficialmente sobre el atrayente lugar, como si el poema se estuviera esforzando en decorar una naturaleza muerta o inexpresiva, si pensamos así, estaríamos olvidando un elemento que los versos refuerzan cuando enfatizan el cromatismo y la musicalidad, este elemento se encuentra plasmado en la alusión que se hace a la alegría, a la ensoñación y 
a la quimera como efectos producidos por el vivo paisaje cajamarquino; así, la maravilla magnética de color y sonido, es, además, espacio propicio para el enriquecimiento de la dimensión espiritual:

Ciudad querida, ciudad soñada, yo te venero cual te veneran en la alborada

los tibios rayos del sol que tilda sobre tu cerro de San Cristóbal sus rojas flechas, cual te venera la luna altiva, argentadora de las parejas.

De este modo la ciudad, la naturaleza y el paisaje que se representan en el poema, más que simples decorados llamativos, son virtudes del espacio vital que alientan la dimensión espiritual. "Cajamarca» es así una especie de manifiesto a favor de las ciudades donde la vida urbana y citadina convive con el fomento y el cultivo de la espiritualidad y el crecimiento interior, aquello que hoy en día no se hace en muchas ciudades que se han transformado en prisiones urbanas $\mathrm{o}$, coloquialmente hablando, en «paisajes de fierro y cemento».

\section{Conclusión}

El comentario de estos poemas permite comprender tres constantes que están presentes en el poemario póstumo Extravagancias, sobre todo apreciar que para Corcuera el poeta es quien busca la palabra precisa que contenga y exprese el torbellino de sentimientos que 
desencadena la existencia. También nos comunica que el ejercicio de la poesía no consiste en acomodar palabras para medir su extensión y reconocer su ritmo, sino que significa conocimiento del mundo, testimonio de la experiencia en el mundo; finalmente, nos muestra que el cromatismo y la musicalidad poéticas se enriquecen con la dimensión espiritual.

Por lo expuesto, hago un llamado a los especialistas reunidos en este congreso para que exhorten a las nuevas generaciones a leer y conocer la poesía de Marco Antonio Corcuera, un poeta cuya palabra poética necesita ser redescubierta. 


\section{Bibliografía}

CORCUERA, Marco Antonio. "Qué es la poesía». Cuadernos Trimestrales de Poesía, No 47. Trujillo, 1972, s. p.

. Extravagancias. Trujillo, Fondo

Editorial de la Universidad Privada Antenor Orrego, 2016.

PAZ, Octavio. El arco y la lira. México D. F., Fondo de Cultura Económica, 1956. 